\title{
Embedded Research in the Learning Healthcare System: Ongoing Challenges and Recommendations for Researchers, Clinicians, and Health System Leaders
}

\author{
Michael K. Gould, ${ }^{1}$, Adam L. Sharp ${ }^{1,2,3}$, Huong Q. Nguyen ${ }^{1,2}$, Erin E. Hahn $n^{1,2}$, \\ Brian S. Mittman' , Ernest Shen', Angel C. Alem', and Michael H. Kanter ${ }^{2}$
}

'Division of Health Services Research and Implementation Science, Department of Research and Evaluation, Kaiser Permanente Southern California Pasadena, CA, USA; ${ }^{2}$ Kaiser Permanente Bernard J. Tyson School of MedicinePasadena, CA, USA; ${ }^{3}$ Southern California Permanente Medical GroupPasadena, CA, USA.

Embedded research is an innovative means to improve performance in the learning healthcare system (LHS). However, few descriptions of successful embedded research programs have been published. In this perspective, we describe the Care Improvement Research Team, a mature partnership between researchers and clinicians at Kaiser Permanente Southern California. The program supports a core team of researchers and staff with dedicated resources to partner with health system leaders and practicing clinicians, using diverse methods to identify and rectify gaps in clinical practice. For example, recent projects helped clinicians to provide better care by reducing prescribing of unnecessary antibiotics for acute sinusitis and by preventing readmissions among the elderly. Embedded in operational workgroups, the team helps formulate research questions and enhances the rigor and relevance of data collection and analysis. A recent business-case analysis cited savings to the organization of over $\$ 10$ million. We conclude that embedded research programs can play a key role in fulfilling the promise of the LHS. Program success depends on dedicated funding, robust data systems, and strong relationships between researchers and clinical stakeholders. Embedded researchers must be responsive to health system priorities and timelines, while clinicians should embrace researchers as partners in problem solving.

$\mathrm{J}$ Gen Intern Med 35(12):3675-80

DOI: $10.1007 / \mathrm{s} 11606-020-05865-4$

() Society of General Internal Medicine 2020

$\mathrm{E}$ mbedded research is rapidly gaining traction as an innovative means to improve care delivery in the learning healthcare system (LHS). ${ }^{1}$ Many researchers are eager to see their work lead to improvements in clinical practice, while

Received January 20, 2020

Accepted April 16, 2020

Published online May 29, 2020 some visionary health system leaders recognize that embedded research adds value to daily operations. A recent national conference brought together health system leaders, researchers, and other clinical stakeholders to discuss the "state of the art" of embedded research. One important gap identified during pre-conference planning is that very few descriptions of successful embedded research programs have been published. ${ }^{2,}{ }^{3}$ In this paper, we describe the Care Improvement Research Team (CIRT), a mature research-operations partnership that has been in place at KPSC since 2012. We also provide recommendations for both embedded researchers and clinical stakeholders based on our experience.

\section{SETTING}

KPSC is a fully integrated healthcare system that serves a socio-demographically diverse population of over 4.6 million members. The system currently includes over 7600 physicians and 26,000 nurses, who provide care at 15 hospitals and 231 medical office buildings. Clinical care is administered and delivered under a federated model, in which practicing physicians serve as leaders at both the local and regional levels. Most day-to-day operational decisions are made by leaders of local "medical service areas," while regional leadership provides strategic direction, sets clinical policy, and supervises programs for quality improvement and population health management.

Within the regional offices, the Department of Research and Evaluation employs approximately 30 research scientists and over 300 support staff, including five core scientists and 6-8 full-time equivalents of support staff who constitute the CIRT program. While the department primarily functions as a traditional soft-money academic research unit, the CIRT program was founded by executive leadership with hard-money support to build capacity for embedded research that simultaneously aims to improve health system performance and create valid scientific knowledge. CIRT scientists have training and experience in clinical medicine, nursing, health services research, sociology, 
implementation science, clinical epidemiology, and biostatistics.

\section{PROGRAM DESCRIPTION}

Like many other organizations, KPSC has developed a number of mechanisms to execute the core functions of the LHS. ${ }^{4}$ Practicing physicians play key roles in this ecosystem. By serving on local or regional improvement teams, they identify important clinical questions, help to set goals and priorities, provide feedback about intervention fit and feasibility, and work to implement changes in practice. To integrate research into the fabric of the LHS at KPSC, the CIRT program adopted a strategy of embedding research scientists with relevant expertise into existing operational teams, reasoning that such groups were already empowered to lead improvement efforts (Table 1). Once embedded, they provide expert consultation to help formulate operational research questions and enhance the rigor and relevance of subsequent data collection and analyses. For example, a CIRT project performed in partnership with the Readmissions Steering Committee found that to reduce the frequency of 30-day readmissions for older adults, the optimal timing of a post-hospital outpatient followup visit was within 7 days of discharge, resulting in a systemwide change in policy that affected over 70,000 patients each year. ${ }^{5}$

CIRT research scientists meet monthly with executive sponsors to identify and prioritize opportunities for health system-based research. In partnership with clinical stakeholders, they design and execute studies to describe, diagnose, and reduce undesirable variation in clinical practices, develop strategies to implement evidence-supported interventions and de-implement ones that are ineffective, and participate in the evaluation of new and existing programs and practices, when more rigorous research methods are deemed valuable. Ultimately, decisions that affect practice are made by health system leaders, with input from CIRT scientists and clinical stakeholders. As one example, team members evaluated the effect of a novel online Personal Action Plan (oPAP) that used the kp.org patient portal to remind eligible patients when they were due for routine preventive services such as annual pneumonia vaccination, hemoglobin A1c testing, and screening for breast, cervical, and colorectal cancer. In this evaluation, the adjusted odds of timely cancer screening and $\mathrm{HbAlc}$ testing were $6 \%$ to $12 \%$ higher among oPAP users than non-users. ${ }^{6}$

CIRT investigators are expected to support approximately $50 \%$ of their effort with external grant funding, while the remainder of their time is devoted to operational projects and supported by internal funds. This enables each investigator to maintain a professional identity as a researcher, while fostering synergies between internally and externally funded projects. Increasingly, questions of importance to clinical stakeholders are becoming well aligned with the interests of funding agencies. For example, an ongoing organizational effort to reduce unnecessary hospitalizations for low-risk patients with chest pain led to a successful grant proposal to study the implementation of a validated risk assessment model using a computerized decision support tool in the electronic health record (EHR). ${ }^{7}$

Thematic areas of emphasis reflect the clinical interests and methodological expertise of team members. These include (1) enabling chronic disease self-management through the adoption of health communication technologies; ${ }^{8}$ (2) finding ways to support patients with complex needs ${ }^{9}$ or serious illness and their caregivers; ${ }^{10}$ (3) improving care for cancer patients and survivors; ${ }^{11}$ (4) using computerized decision support to improve emergency and acute care; ${ }^{12}$ (5) reducing unnecessary, low-value care, ${ }^{13}$ and (6) addressing the social determinants of health. ${ }^{14}$

CIRT projects leverage a diverse set of research methods. Consistent with the VA QUERI model, ${ }^{15}$ most CIRT projects follow a process that begins with an analysis of EHR data to identify undesirable practice variation and gaps in care delivery. For example, one such analysis found that antibiotics were prescribed in $89 \%$ of all cases of acute sinusitis, representing substantial overuse and providing an opportunity to deimplement a low-value practice. ${ }^{16}$ As a next step, a qualitative study identified multiple determinants of over-prescribing, including patient expectations, limited time for discussion, and provider concerns about patient satisfaction scores. ${ }^{17} \mathrm{Sub}$ sequently, a stepped-wedge, pragmatic clinical trial demonstrated that a multi-pronged intervention including provider education and computerized decision support reduced unnecessary antibiotic prescribing by approximately $20 \%{ }^{18}$ Of note, the best practice alert developed for this study remains in use throughout the health system and continues to influence care.

\section{PROGRAM EVALUATION}

The traditional research metrics of publications and external grants do not fully capture the contributions of research that is embedded in health systems. Accordingly, we conceptualize the CIRT program as a collection of specific projects, each one evaluated using a rubric that includes five domains: innovation, actionable findings, efforts to disseminate the findings internally, planned or ongoing implementation activities, and improvements in quality (processes and outcomes) and affordability (Fig. 1). CIRT scientists review these metrics quarterly with executive sponsors and assemble a slate of new and ongoing projects twice yearly for sponsors to prioritize.

To date, demonstrated improvements in quality include increased uptake of screening for depression and anxiety among breast cancer survivors, decreased prescribing of opioids for patients with non-cancer pain, and greater use of tools 
Table 1 Examples of CIRT Projects with Clinical/Operational Partners and Impact

\begin{tabular}{|c|c|c|c|c|}
\hline Topic & $\begin{array}{l}\text { Idea } \\
\text { generation }\end{array}$ & Organizational partner & Funding & Impact \\
\hline \multicolumn{5}{|c|}{ Observational studies to encourage best practices } \\
\hline $\begin{array}{l}\text { Prevention of venous } \\
\text { thromboembolism }\end{array}$ & $\begin{array}{l}\text { Health } \\
\text { system }\end{array}$ & $\begin{array}{l}\text { Regional VTE Steering } \\
\text { Committee }\end{array}$ & Internal (CIRT) & $\begin{array}{l}\text { Identified optimal timing of post- } \\
\text { discharge follow-up visit to reduce the } \\
30 \text {-day readmission rate } \\
\text { Identified missed opportunities for } \\
\text { chemical prophylaxis; validated existing } \\
\text { risk assessment models; and } \\
\text { implemented decision support in EHR }\end{array}$ \\
\hline $\begin{array}{l}\text { Biomarker testing for breast } \\
\text { cancer survivors }\end{array}$ & Investigator & Chiefs of Oncology & Internal (CIRT) & $\begin{array}{l}\text { Identified substantial variability in } \\
\text { testing at both the medical center and } \\
\text { provider levels; attempted to reduce } \\
\text { inappropriate prescribing with limited } \\
\text { success }\end{array}$ \\
\hline Lung cancer screening & $\begin{array}{l}\text { Health } \\
\text { system }\end{array}$ & $\begin{array}{l}\text { Enhanced Implementation } \\
\text { of Lung Cancer Screening } \\
\text { Steering Committee }\end{array}$ & $\begin{array}{l}\text { Internal (CIRT) } \rightarrow \text { Lung } \\
\text { Cancer Research } \\
\text { Foundation }\end{array}$ & $\begin{array}{l}\text { Identified substantial underuse as well as } \\
\text { inappropriate use of screening; } \\
\text { implemented new standardized order sets } \\
\text { to reduce use among low-risk patients } \\
\text { who do not meet standard eligibility } \\
\text { criteria }\end{array}$ \\
\hline $\begin{array}{l}\text { Models of cancer } \\
\text { survivorship care }\end{array}$ & Investigator & Chiefs of Oncology & Internal $(\mathrm{CIRT}) \rightarrow \mathrm{NCI}$ & $\begin{array}{l}\text { Identified a novel model of survivorship } \\
\text { care that is feasible and acceptable to } \\
\text { implement }\end{array}$ \\
\hline $\begin{array}{l}\text { Overuse of antibiotics for } \\
\text { acute sinusitis }\end{array}$ & $\begin{array}{l}\text { Health } \\
\text { system }\end{array}$ & Chiefs of Primary Care & Internal (CIRT) & $\begin{array}{l}\text { Improved stewardship by identifying } \\
\text { root causes of overuse and implementing } \\
\text { education and decision support }\end{array}$ \\
\hline \multicolumn{5}{|l|}{ Pragmatic trials } \\
\hline $\begin{array}{l}\text { Physical activity coaching } \\
\text { for COPD }\end{array}$ & Investigator & $\begin{array}{l}\text { Pulmonary Rehabilitation } \\
\text { Work Group }\end{array}$ & $\begin{array}{l}\text { Internal }(\mathrm{CIRT}) \rightarrow \\
\text { PCORI-funded } \\
\text { pragmatic trial }(\$ 4 \mathrm{M})\end{array}$ & $\begin{array}{l}\text { Completed externally funded trial of } \\
\text { home-based physical activity coaching } \\
\text { that improved activity but did not reduce } \\
\text { acute care utilization or death }\end{array}$ \\
\hline $\begin{array}{l}\text { Step-wedge trial of a device } \\
\text { to reduce the frequency of } \\
\text { unplanned Cesarean section }\end{array}$ & $\begin{array}{l}\text { Health } \\
\text { system }\end{array}$ & $\begin{array}{l}\text { Medical Technology } \\
\text { Assessment/Deployment } \\
\text { Committees }\end{array}$ & Internal (CIRT) & $\begin{array}{l}\text { Prevented deployment of poorly } \\
\text { tolerated device, leading to substantial } \\
\text { cost avoidance }\end{array}$ \\
\hline $\begin{array}{l}\text { Self-activated online } \\
\text { reminders for CRC screening }\end{array}$ & $\begin{array}{l}\text { Health } \\
\text { system }\end{array}$ & $\begin{array}{l}\text { Online Personal Action } \\
\text { Plan Team }\end{array}$ & Internal (CIRT) & $\begin{array}{l}\text { Improved uptake and timeliness of } \\
\text { screening for colorectal cancer }\end{array}$ \\
\hline $\begin{array}{l}\text { Evaluation of patients with } \\
\text { pulmonary nodules }\end{array}$ & $\begin{array}{l}\text { Health } \\
\text { system }\end{array}$ & $\begin{array}{l}\text { Regional "SureNet" } \\
\text { Program }\end{array}$ & $\begin{array}{l}\text { Internal }(\mathrm{CIRT}) \rightarrow \\
\text { PCORI-funded prag- } \\
\text { matic trial }(\$ 14.5 \mathrm{M})\end{array}$ & $\begin{array}{l}\text { Extended reach of existing program to } \\
\text { identify patients with nodules who } \\
\text { require follow-up }\end{array}$ \\
\hline
\end{tabular}

CIRT, Care Improvement Research Team; COPD, chronic obstructive pulmonary disease; CRC, colorectal cancer; EHR, electronic health record; NCI, National Cancer Institute; NHLBI, National Heart, Lung and Blood Institute; NIH, National Institutes of Health; PCORI, Patient-Centered Outcomes Research Institute

for individualized risk assessment for conditions such as hospital-associated venous thromboembolism. In addition, a recent internal analysis cited savings to the organization of over \$10 million for several CIRT projects that helped to reduce low-value care, such as advanced imaging for patients with minor head trauma.

\section{ONGOING CHALLENGES AND RECOMMENDATIONS}

To date, the program has made substantial contributions to improvements in health system performance and helped to create new scientific knowledge by sharing findings in the public domain.

Multiple factors contribute to program success, including access to data from the EHR and being embedded in a healthcare system with an organizational culture that values performance improvement. The ability to access rich, longitudinal data from the EHR provides opportunities to identify gaps in care, monitor trends in utilization, and measure clinical outcomes. The hard-money commitment provides stable funding and allows researchers to devote a substantial fraction of their effort to operationally focused projects instead of relying exclusively on external grant support. Lastly, the 


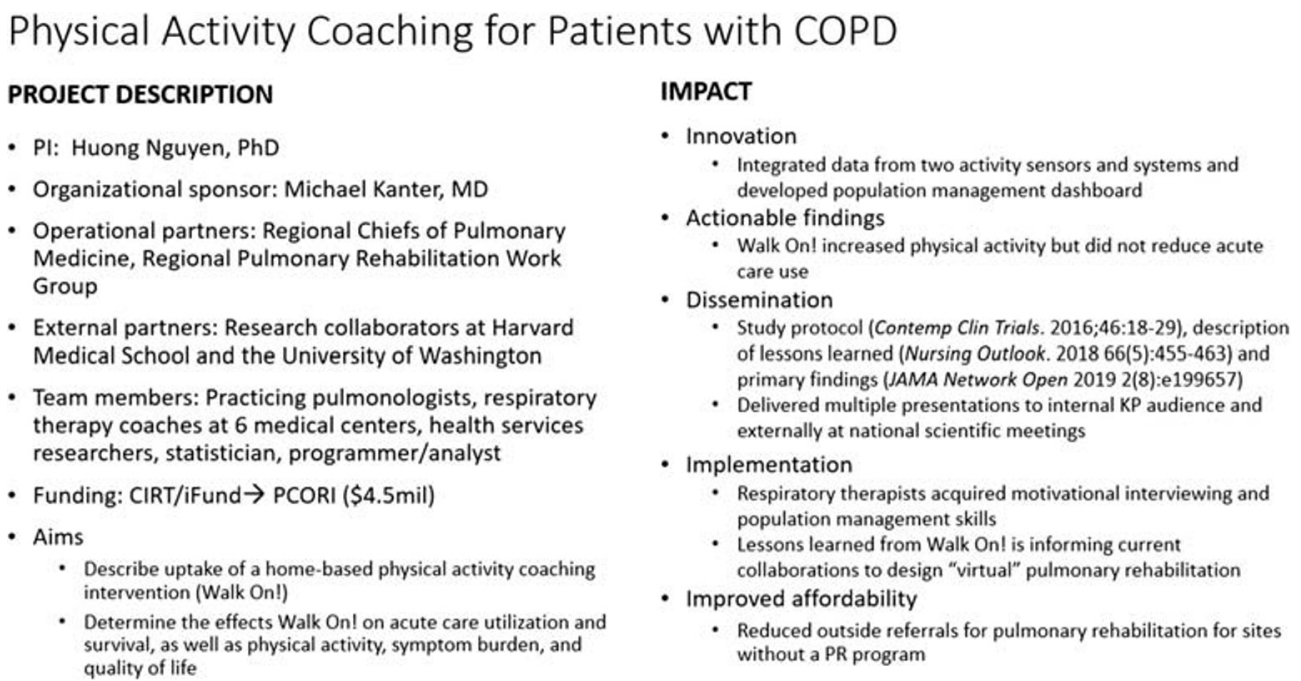

Figure 1 Rubric used to describe CIRT projects and their impact.

program has worked diligently to cultivate strong relationships with its executive sponsors and relies on them to "make things happen" when leadership support is necessary. Equally important are the relationships with practicing physicians, who make critical contributions as leaders and members of multidisciplinary improvement teams.

A number of similar programs have been described in other healthcare systems, including Kaiser Permanente Northern California (KPNC), ${ }^{2}$ the University of California, San Francisco (UCSF), ${ }^{3}$ the Department of Veterans Affairs (VA), ${ }^{18}$ and NYU Langone Health. ${ }^{19}$ What distinguishes the CIRT program is its core team of researchers and staff with dedicated time and resources to work in an ongoing partnership with executive sponsors and practicing clinicians, using diverse research methods to identify, understand, and address care gaps in real-world clinical practice.
To sustain and spread programs for embedded research in the LHS, several challenges need to be addressed (Table 2). These challenges include uncertain funding, misaligned timelines, understandably low tolerance for experimental disruption in busy clinical settings, and a limited supply of individuals trained in embedded research methods.

In our view, embedded research should be funded by health systems, and it is highly preferable to have a dedicated stream of funding over several years to avoid interruptions in ongoing projects and sustain programs administratively. The internal funding is justified not only by the anticipated return on investment but also by the recognition that embedded research is an engine of health system innovation.

The clinical and operational imperative for rapid-cycle learning can be negotiated by developing a research pipeline that includes both short-term and long-term projects, each with specific deliverables. A staggered timeline would ideally

Table 2 Challenges of Embedded Research and Recommendations for Researchers, Practicing Clinicians, and Health System Leaders

\begin{tabular}{|c|c|}
\hline Challenge & Recommendations \\
\hline Uncertain funding & $\begin{array}{l}\text { Health system leaders: provide internal funding to support researchers and staff, justified by return on investment } \\
\text { and recognition that research is an engine of health system innovation } \\
\text { Researchers: respond to grant opportunities from external funding agencies that target problems that align with } \\
\text { health system priorities and capabilities }\end{array}$ \\
\hline Misaligned timelines & $\begin{array}{l}\text { Leaders, clinicians, and researchers: negotiate timelines that are both responsive to health system needs and } \\
\text { realistic to accomplish; develop a portfolio of projects with staggered timelines to allow for learning at regular } \\
\text { intervals }\end{array}$ \\
\hline $\begin{array}{l}\text { Low organizational tolerance } \\
\text { for disruption }\end{array}$ & $\begin{array}{l}\text { Health system leaders: recognize important limitations of conventional before vs. after comparisons, i.e., regression } \\
\text { to the mean, secular trends; be open to randomization at patient level or cluster randomization when feasible } \\
\text { Researchers: embrace less disruptive and quasi-experimental designs, e.g., stepped-wedge trials, interrupted time } \\
\text { series analyses, regression discontinuity approaches } \\
\text { Clinicians: be willing to embrace designs such as cluster randomization; consider potential benefits to research and } \\
\text { quality improvement of entering structured data into patient registries }\end{array}$ \\
\hline $\begin{array}{l}\text { Limited supply of embedded } \\
\text { researchers } \\
\text { Silos between research and } \\
\text { operations }\end{array}$ & $\begin{array}{l}\text { Health system leaders: provide real-world training opportunities; participate in sponsored training programs } \\
\text { Researchers: develop proficiency in the } 33 \text { core competencies of learning health system research } \\
\text { Health system leaders: provide access to operational workgroups, practicing clinicians, and decision-makers; } \\
\text { codify roles and responsibilities of researchers and other team members; clarify boundaries between QI and } \\
\text { research } \\
\text { Researchers: cultivate "soft" skills of listening and collaborating; do not be afraid to challenge conventional } \\
\text { wisdom } \\
\text { Clinicians: be open to working with embedded researchers to evaluate novel practices and programs as part of } \\
\text { routine clinical care } \\
\text { Leaders, clinicians, and researchers: build authentic relationships based on mutual trust }\end{array}$ \\
\hline
\end{tabular}


provide a stream of research findings that could be reviewed and acted upon by clinical leaders at regular intervals. Similarly, while health system leaders may have limited tolerance for experimental or quasi-experimental trials of care delivery interventions, it can be argued that such experiments are not fundamentally different than the typical before vs. after comparisons that characterize most operational evaluations, but allow for much stronger inferences and presumably better decisions.

To address the limited supply of embedded researchers, AcademyHealth has administered a training program in Delivery System Science since 2013. More recently, the Agency for Healthcare Research and Quality and the Patient-Centered Outcomes Research Institute have jointly sponsored a K12 training program to support mentored, patient-centered outcomes research within the LHS. In tandem, thought leaders have defined 33 core competencies for embedded researchers. ${ }^{20}$ These training programs and core competencies should help build capacity gradually over time, but more rapid dissemination will necessarily occur at the health system level.

Above all, embedded researchers need to be responsive to health system priorities and timelines. It is therefore essential to be flexible with regard to topic and nimble in moving from project to project as organizational priorities shift over time. While not mandatory, it helps to be a generalist with multiple areas of interest and training in diverse research methods. Ultimately, the most important tools of the embedded researcher are the "soft" skills of listening, asking questions, (politely) challenging the conventional wisdom, and working with others as equal members of the team.

Health system leaders and practicing physicians who wish to leverage the rigor of research to improve organizational performance should embrace embedded researchers as genuine partners in problem solving. They should facilitate interactions with influential clinical stakeholders, provide access to existing operational workgroups, and empower researchers by giving them a seat at the table where decisions are made. The roles and responsibilities of researchers as members of the organizational team should be codified in the system's governance structure, in particular to clarify any boundaries between QI and research.

\section{CONCLUSIONS}

The promise of the LHS is to enhance population health by improving the quality and affordability of care. Embedded research programs like CIRT can play a key role in fulfilling this promise, by working collaboratively with practicing clinicians and other stakeholders to generate, disseminate, and translate new evidence into practice. The role of embedded researchers is to help clinicians improve care by bringing research skills and rigor to the existing quality improvement enterprise. Program success depends on a number of factors, including dedicated funding, robust data systems, and strong relationships between members of the embedded research team and clinical stakeholders.

Acknowledgments: The authors gratefully acknowledge the contributions of Nancy Gin, MD, Ben Broder, MD, PhD, Jerry Spicer, DNP, $R N$, and Patti Harvey, RN, MPH, who serve as the current executive sponsors for the CIRT program, as well as former team members and sponsors including Benjamin Chu, MD (founding sponsor), Nirav Shah, MD, MPH, Carly Parry, PhD, MSW, MA, Tania Tang, PhD, $M P H$, and Shayna Henry, PhD.

Corresponding Author: Michael K. Gould, Division of Health Services Research and Implementation Science, Department of Research and Evaluation, Kaiser Permanente Southern California Pasadena, CA, USA (e-mail: Michael.K.Gould@kp.org).

Funding Information The CIRT program is funded by Kaiser Permanente Southern California.

\section{Compliance with Ethical Standards:}

Conflict of Interest: Dr. Gould reports receiving royalties from UpToDate for co-authoring topics on lung cancer diagnosis and staging, and research funding through his institution from Medial EarlySign to develop lung cancer risk models. The other authors have no conflicts to disclose.

\section{REFERENCES}

1. Greene SM, Reid RJ, Larson EB. Implementing the learning health system: from concept to action. Annals of Internal Medicine. 2012;157(3):207-210.

2. Lieu TA, Madvig PR. Strategies for building delivery system science in an integrated health care system. Journal of General Internal Medicine 2019; 34:1043-1047.

3. Gonzalez R, Moriates C, Lau C, Valencia V, Imershein S, Rajkomar A, et al. Caring Wisely: a program to support frontline clinicians and staff in improving healthcare delivery and reducing costs. Journal of Hospital Medicine 2017; 12:662-667.

4. Bindman A. How learning health systems learn: lessons from the field. AHRQ Pub No. 19-0047, April 2019. Available at: https://www.ahrq.gov/ learning-health-systems/how-lhs-learn.html. Accessed November 12, 2019.

5. Shen E, Koyama SY, Huynh DN, Watson HL, Mittman B, Kanter MH, Nguyen HQ. Association of a dedicated post-hospital discharge follow-up visit and 30-day readmission risk in a Medicare Advantage population. JAMA Internal Medicine 2017; 177:132-135.

6. Henry SL, Shen E, Ahuja A, Gould MK, Kanter MH. The online personal action plan: a tool to transform patient-enabled preventive and chronic care. American Journal of Preventive Medicine 2016; 51:71-77.

7. Sharp AL, Wu Y-L, Shen E, Redberg R, Lee M-S, Ferencik M, Natsui S, Zeng C, Kawatkar A, Gould MK, Sun BC. Prospective validation of the HEART score for suspected acute coronary syndrome in US community emergency departments. Journal of the American College of Cardiology 2018; 72:1875-1877.

8. Nguyen HQ, Moy M, Liu AI, Fan VS, Gould MK, Desai S, Towner W, Yuen G, Lee JS, Park SJ, Xiang AH. Effect of physical activity coaching on acute care and survival in chronic obstructive pulmonary disease: A pragmatic randomized clinical trial. JAMA Network Open 2019;2: e199657.

9. Davis AC, Shen E, Shah NR, Glenn BA, Ponce N, Telesca D, Gould MK, Needleman J. Segmentation of high-cost adults in an integrated healthcare system based on empirical clustering of acute and chronic conditions. Journal of General Internal Medicine 2018; 33:2171-2179.

10. Wang S, Liu AI, Lee JS, Khang P, Rosen R, Reinke LF, Mularski RA, Nguyen HQ. End-of-life care in patients exposed to home-based palliative care versus hospice only. Journal of the American Geriatrics Society 2019; 67:1226-1233.

11. Hahn EE, Munoz-Plaza CE, Schottinger JE, Brasfield FM, Gould MK, Parry C. Developing innovative models of care for cancer survivors: use of 
implementation science to guide evaluation of appropriateness and feasibility. Supportive Care in Cancer 2019; 27:1737-1745.

12. Sharp AL, Huang BZ, Tang T, Melnick ER, Venkatesh AK, Kanter MH Gould MK. Implementation of the Canadian head CT rule and its association with use of computed tomography among patients with head injury. Annals of Emergency Medicine 2018; 71:54-63.

13. Hahn EE, Tang T, Lee JS, Munoz-Plaza C, Shen E, Rowley B, Maeda JL, Mosen DM, Ruckdeschel JC, Gould MK. Use of post-treatment imaging and biomarkers in early stage breast cancer survivors: inappropriate surveillance or necessary care? Cancer 2016; 122:908-916.

14. Lewis CC, Thompson EE, and Sharp AL. A survey of basic resource needs: results from a sample of Kaiser Permanente Southern California members. Social Needs Network for Evaluation and Translation (SONNET). Jun 2019. Available at: http://sonnet.kaiserpermanente.org/ index.html. Accessed December 11, 2019.

15. Atkins D, Kilbourne AM, Shulkin D. Moving from discovery to systemwide change: the role of research in a learning health care system: experience from three decades of health systems research in the veterans health administration. Annual Review of Public Health 2017; 38:467-487.

16. Sharp AS, Klau MH, Keschner D, Macy E, Tang T, Shen E, MunozPlaza C, Kanter M, Silver MA, Gould MK. Low-value care for acute sinusitis encounters: who's choosing wisely? American Journal of Managed Care 2015; 21:479-485.

17. Munoz-Plaza CE, Parry C, Hahn EE, Tang T, Nguyen HQ, Gould MK, Kanter MH, Sharp AS. Integrating qualitative methods into care improvement efforts within a learning health system. Health Research Policy and Systems 2016; 14:63.

18. Sharp AL, Shen E, Chen R, Radecki RP, Kanter MH, Gould MK. Improving antibiotic stewardship: a stepped-wedge cluster randomized trial. American Journal of Managed Care 2017;23: e294-e299.

19. Horwitz LI, Kuznetsova M, Jones SA. Creating a learning health system through rapid-cycle, randomized testing. New England Journal of Medicine 2019; 381:1175-1179.

20. Forest CB, Chesley FD Jr, Tregear ML, Mistry KB. Development of the learning health system researcher core competencies. Health Services Research 2018; 53:2615-2632.

Publisher's Note: Springer Nature remains neutral with regard to jurisdictional claims in published maps and institutional affiliations. 